Trinity University

Digital Commons @ Trinity

Psychology Faculty Research

Psychology Department

$9-2015$

\title{
Effectiveness of a Peer-Delivered Dissonance-Based Program in Reducing Eating Disorder Risk Factors in High School Girls
}

Anna C. Ciao

J. D. Latner

K. E. Brown

D. S. Ebneter

Carolyn Becker

Trinity University, cbecker@trinity.edu

Follow this and additional works at: https://digitalcommons.trinity.edu/psych_faculty

Part of the Psychology Commons

Publication Details

International Journal of Eating Disorders

\section{Repository Citation}

Ciao, A.C., Latner, J.D., Brown, K.E., Ebneter, D.S., \& Becker, C.B. (2015). Effectiveness of a peer-delivered dissonance-based program in reducing eating disorder risk factors in high school girls. International Journal of Eating Disorders, 48(6), 779-784. doi: 10.1002/eat.22418

This Post-Print is brought to you for free and open access by the Psychology Department at Digital Commons @ Trinity. It has been accepted for inclusion in Psychology Faculty Research by an authorized administrator of Digital Commons@ Trinity. For more information, please contact jcostanz@trinity.edu. 
Effectiveness of a peer-delivered dissonance-based program in reducing eating disorder risk factors in high school girls

\author{
Anna C. Ciao, ${ }^{1,2}$ Janet D. Latner, ${ }^{2}$ Krista E. Brown, ${ }^{2}$ Daria S. Ebneter, ${ }^{3}$ \& Carolyn B. Becker ${ }^{4}$ \\ ${ }^{1}$ Western Washington University, Department of Psychology, Bellingham, WA; ${ }^{2}$ The \\ University of Hawaii at Manoa, Department of Psychology, Honolulu, HI; ${ }^{3}$ The University of \\ North Carolina, School of Medicine, Chapel Hill, NC, ${ }^{4}$ Trinity University, Department of \\ Psychology, San Antonio, TX.
}

Address correspondence to: Anna Ciao, Ph.D., Anna.Ciao@wwu.edu; Western Washington University, Department of Psychology, MS-9172, 434 Academic Instruction Center, 516 High Street, Bellingham, WA 98225.

\begin{abstract}
word count: 190
Manuscript word count: 1,552
\end{abstract}

PEER-LED EATING DISORDER RISK REDUCTION 


\begin{abstract}
Objective: This pilot study investigated the feasibility, acceptability, and effectiveness of a peerled dissonance-based eating disorders (ED) prevention/risk factor reduction program with high school girls. Method: Ninth grade girls $(n=50)$ received the peer-led program within the school curriculum. A quasi-experimental design was utilized to assess changes in ED risk factors preand post-intervention compared to waitlist control. Participants were followed through 3-month follow-up. Results: Peer-leader adherence to an intervention manual tailored for this age group was high. The intervention was rated as highly acceptable, with a large proportion of participants reporting that they enjoyed the program and learned and applied new information. Intervention participants exhibited significantly greater pre-post reductions in a majority of risk-factor outcomes compared to waitlist controls. When groups were combined to assess program effects over time there were significant pre-post reductions in a majority of outcomes that were sustained through 3-month follow-up. Conclusions: This pilot study provides tentative support for the effectiveness of using peer leaders to implement an empirically supported ED risk factor reduction program in a high school setting. Additional research is needed to replicate results in larger, better-controlled trials with longer follow-up.
\end{abstract}

Keywords: Eating disorders; risk factor reduction; cognitive dissonance; peer-leaders; high school 
Effectiveness of a peer-delivered dissonance-based program in reducing eating disorder risk factors in high school girls

Dissonance-based interventions (DBIs) are clearly efficacious in reducing eating disorder (ED) risk factors among adolescent girls ${ }^{1}$ and college-aged women ${ }^{2-6}$ and have been shown to reduce the onset of EDs over multi-year follow-up. ${ }^{7}$ DBIs challenge beliefs in the current beauty ideal through verbal, written, and behavioral "counterattitudinal" exercises to create cognitive dissonance $^{8}$ and subsequent positive change in attitudes and behaviors.

Given DBIs’ efficacy, recent research has focused on dissemination. Many effectiveness trials use community providers to deliver interventions, which improves sustainability over time. DBIs can be effectively delivered using community providers with brief training, including highschool and college staff. ${ }^{9-12}$ Given limitations on staff and time needed for training, selected groups (e.g., high-risk/highly body-dissatisfied females) are frequently targeted in effectiveness research, limiting generalizability to broader populations.

A series of effectiveness trials overcame this limitation by training college-aged leaders to deliver DBIs to peers of all risk levels, yielding positive effects on ED risk factors through long-term follow-up. ${ }^{13-16}$ Although intervention effects are sometimes smaller with peer-led DBI (PL-DBI) relative to professional delivery, ${ }^{17} \mathrm{PL}$-DBIs appear to be a highly sustainable model for large-scale intervention delivery, ${ }^{18}$ in part because they rely on community partnership and other principles of dissemination science. ${ }^{19,20}$

Little is known about the feasibility of PL-DBIs with younger audiences, ${ }^{21,22}$ yet peer leaders are effective in delivering a variety of school-based health education interventions. ${ }^{23}$ Prevention in mid-/late-adolescence is essential given this high-risk period for developing EDs, ${ }^{24}$ and ED risk-reduction programming in this age range tends to be school-based and includes both 
high- and low-risk individuals. ${ }^{25-28}$ Thus, the current pilot study investigated the effectiveness of a school-based, PL-DBI in reducing ED risk factors in high- and low-risk adolescent girls. Research methods were collaboratively determined with the participating high school to create a program that was both evidence-based and acceptable to the school community. It was hypothesized that high-schoolers could successfully deliver a PL-DBI (1) with fidelity to an intervention manual, (2) that was acceptable to students and staff, and (3) that would produce positive effects on ED risk-factor outcomes.

\section{Method}

\section{Participants and Procedures}

All $9^{\text {th }}$ grade girls in the participating high school received the PL-DBI as a mandatory health-class component $\left[n=51 ; M(S D)\right.$ age $=13.98(0.59)$ years; $M(S D)$ BMI $=20.92(2.98) \mathrm{kg} / \mathrm{m}^{2}$; 40\% Caucasian, 32\% Hawaiian or Pacific Islander, 18\% Other/Mixed, 10\% Asian]. A quasiexperimental design allocated groups by classroom based on scheduling feasibility. Three health classes during the first school-quarter $(n=25)$ were allocated to the active group, and three health classes during the second quarter $(n=26)$ were allocated to the waitlist-control group. Two 1.5-hour DBI sessions were held 2 days apart. The two-session PL-DBI content has been previously described in detail. ${ }^{13}$ A published PL-DBI guide for college students ${ }^{29}$ was modified to include examples/language relevant to high school culture. A section on cultural/ethnic beauty ideals was added to capture the diversity of the participating high school. Ten peer-leaders (nine $12^{\text {th }}$ and one $11^{\text {th }}$ grader) recruited by the school-counselor completed 12-hours of training over a two-day period (training methods previously described). ${ }^{13-16}$ Peer-leaders were screened for ED symptoms using the Eating Disorders Examination Questionnaire $\left(\mathrm{EDEQ}^{30}\right)$. 
Groups of 3-4 peer-leaders led in-class intervention sessions with 6-12 group members. Each peer-leader team led one active and one waitlist group. The university Institutional Review Board approved all research procedures. Passive parental consent was obtained.

\section{Measures}

Intervention Adherence. Two independent raters coded audio-recorded sessions for the presence/absence of each intervention component. Kappa ratings were calculated to estimate inter-rater reliability.

Program Acceptability. Post-intervention questions assessed acceptability (rated on a 15 Likert scale from $1=$ not at all to 5=very much): (1) "how much did you enjoy the program"; (2) "how much did the program teach you new information."

Risk-Factor Outcomes. All participants completed assessments before the study began (baseline) and one week later (active group post-intervention). At that time, the waitlist group received the intervention and was re-assessed one week later (waitlist post-intervention). All participants were re-assessed three months post-intervention (see Figure 1). Multiple measures, selected based on use in previous DBI trials, assessed four ED risk-factor outcomes. The Ideal Body Stereotype Scale-Revised (IBSS-R ${ }^{31}$ ) and the two internalization subscales (Internalization-General, Internalization-Athlete) of the Sociocultural Attitudes Toward Appearance Questionnaire-3 (SATAQ- $3^{32}$ ) assessed thin-ideal internalization. The 8-item Body Shape Questionnaire $\left(\mathrm{BSQ}^{33,34}\right)$ and the Weight Concern and Shape Concern combined subscales of the EDEQ (EDEQ-WSC ${ }^{30}$ ) assessed body dissatisfaction. The Eating Attitudes Test (EAT-26 ${ }^{35}$ ) and the global score on the EDEQ (EDEQ-Total) assessed eating pathology. The Dieting subscale of the EAT-26 (EAT-Diet) and the Restraint subscale of the EDEQ (EDEQ-R) assessed dietary restraint. Cronbach's alpha of all measures in this sample was 
acceptable (IBSS-R=0.76, SATAQ-3=0.88, BSQ=0.93, EDEQ-WSC=0.86, EAT-26=0.92, EDEQ-Total=0.95, EAT-Diet=0.93, EDEQ-R=0.83).

\section{Analyses}

The final sample consisted of 50 participants (Active $n=24$; Waitlist $n=26$; see Figure 1 for participant flow). Participants with and without missing post-baseline data did not significantly differ on age, BMI, and baseline risk factor scores (all $p$ s >.30). Nonetheless, baseline values were carried forward to account for missing scores, to conservatively estimate no improvement among individuals who did not complete these assessment points.

The two groups did not differ on age, BMI, and baseline risk factor scores (all $p s>.42$ ). Mixed-design ANOVA models assessed pre-post group differences. Separate models were run for each outcome variable with time as a repeated within-participants factor and intervention group as a between-participants factor. A series of repeated-measures ANOVA models assessed outcome changes across all participants (active/waitlist combined), with time as a withinparticipants factor; significant overall time effects were explored with post-hoc simple contrasts comparing baseline to other time points. All significance tests used a two-tailed alpha of 0.05. Effect sizes are reported using partial- $\eta^{2}$.

\section{Results}

\section{Intervention Adherence}

Peer-leaders conducted sessions with acceptable levels of adherence to the manual, with $M(S D)=88.41 \%(4.61 \%)$ of intervention components covered across all sessions ( $M$ kappa ratings $=0.71)$.

\section{Program Acceptability}


All participants (100\%) indicated they enjoyed the program at least "a little" or more; $60 \%$ reported they enjoyed the program "a lot" or "very much." Most participants (96\%) indicated they learned at least "a little" new information; 68\% reported they learned "a lot" or "very much" new information. Further, $43 \%$ said they were interested in becoming a future peerleader.

\section{Risk-Factor Outcomes}

Pre-Post-Intervention Waitlist Comparison. Table 1 shows means, test statistics, and effect sizes from group-by-time interactions of models. Significant interactions were found for both internalization measures $(p s<.0001)$, body dissatisfaction as assessed by the BSQ-8 $(p=.005)$, eating pathology as assessed by the EAT-26 $(p=.012)$, and dietary restraint as assessed by the EAT-Diet ( $p=.002)$. Effect sizes ranged from medium to large. Interactions were not significant for the EDEQ-WCS, EDEQ-Global, or the EDEQ-R ( $p$ s>.062).

Change Through Follow-Up. Across all participants, there were significant main effects for time on all eight outcome measures with large effect sizes $(p s<.031$; see Table 1 for means, test statistics, and effect sizes). Internalization scores were significantly reduced from baseline to post-intervention but rebounded at follow-up (not significantly different from baseline). This same pattern was found for one measure of eating pathology (EAT-26). For body dissatisfaction, dietary restraint, and the second measure of eating pathology (EDEQ-Total), scores were significantly reduced from baseline to post-intervention; this difference was maintained through follow-up.

\section{Discussion}


This pilot study evaluated the feasibility, acceptability, and effectiveness of a PL-DBI with high school girls. To our knowledge, this is one of the first studies to assess a peer-delivered ED risk factor reduction program within a high school population. ${ }^{21,22}$

Findings support the hypothesis that high schoolers can deliver a PL-DBI with high adherence to an age-tailored intervention manual. Furthermore, post-intervention feedback indicated that the program was considered highly acceptable. Study findings partially supported the hypothesis that a PL-DBI can reduce ED risk factors among high-school girls. Relative to a waitlist control, participants who received the program had greater reductions in scores from preto post-intervention than controls on one or more measures of each ED risk factor, although there was variability in effects within constructs depending on measurement instrument. Withinparticipant analyses assessing all 50 participants after the intervention found improvements in body dissatisfaction, eating pathology, and dietary restraint, sustained at three-months. While these results are encouraging, a controlled comparison at follow-up was not possible, and effect sizes are relatively modest compared to other trials. ${ }^{13-16}$ Discrepancies between measures assessing similar constructs (e.g., EAT-26 and EDEQ) were surprising and encourage caution in interpreting results. Contrary to hypotheses, reductions in thin-ideal internalization, the proposed mechanism for change in DBIs ${ }^{1}$, were not sustained over time.

Several limitations of this study should be noted. The school's desire to allocate participants by classroom/schedule prohibited random allocation to condition. Relatedly, while individual level analyses were conducted, the trial was allocated on a group level but underpowered for analyses at the group level. Further limitations included lack of a long-term waitlist-controlled follow-up and relatively small sample size. Demand characteristics also are a concern in a repeated measures study, and low pre-intervention scores on study measures may 
have created floor effects. Finally, generalizability may be limited, given that the participating school was small, private, rural, and ethnically diverse, although the latter may be considered a strength of this work.

In sum, the current study adds to literature on dissonance-based ED prevention by providing initial evidence of the feasibility, acceptability, and effectiveness of a peer-led delivery system implemented as part of a high-school curriculum. Future research is needed to replicate these results to continue striving toward the dual goals of sustainability in school settings and methodological rigor. 


\section{References}

1. Stice E, Shaw H, Burton E, Wade E. Dissonance and healthy weight eating disorder prevention programs: A randomized efficacy trial. J Consult Clin Psychol 2006;74:263-275.

2. Becker CB, Smith LM, Ciao AC. Reducing eating disorder risk factors in sorority members: A randomized trial. Behav Ther 2005;36:245-253.

3. Green M, Scott N, Diyankova I, Gasser C. Eating disorder prevention: An experimental comparison of high level dissonance, low level dissonance, and no-treatment control. Eat Disord 2005; 13:157-169.

4. McMillan W, Stice E, Rohde P. High- and low-level dissonance-based eating disorder prevention programs with young women with body image concerns: an experimental trial. J Consult Clin Psychol 2011;79:129-134.

5. Mitchell KS, Mazzeo SE, Rausch SM, Cooke KL. Innovative interventions for disordered eating: evaluating dissonance-based and yoga interventions. Int J Eat Disord 2007;40:120128.

6. Roehrig M, Thompson JK, Brannick M, van den Berg P. Dissonance based eating disorder prevention program: A preliminary dismantling investigation. Int J Eat Disord 2006;39:1-10.

7. Stice E, Marti CN, Spoor S, Presnell K, Shaw H. Dissonance and healthy weight eating disorder prevention programs: long-term effects from a randomized efficacy trial. J Consult Clin Psychol 2008;76:329-340.

8. Festinger L. A Theory of Cognitive Dissonance. Illinois: Row Peterson; 1957.

9. Stice E, Rohde P, Gau J, Shaw H. An effectiveness trial of a dissonance based eating disorder prevention program for high-risk adolescent girls. J Consult Clin Psychol 2009;77:825-834. 
10. Stice E, Rohde P, Shaw H, Gau J. An effectiveness trial of a selected dissonance based eating disorder prevention program for female high school students: Long-term effects. J Consult Clin Psychol 2011;79:500-508.

11. Matusek JA, Wendt SJ, Wiseman CV. Dissonance thin-ideal and didactic healthy behavior eating disorder prevention programs: Results from a controlled trial. Int J Eat Disord 2004;36:376-388.

12. Stice E, Butryn ML, Rohde P, Shaw H, Marti CN. An effectiveness trial of a new enhanced dissonance eating disorders prevention program among female college students. Behav Res Ther 2013;51:862-71.

13. Becker CB, Smith LM, Ciao AC. Peer facilitated eating disorder prevention programs: A randomized effectiveness trial of cognitive dissonance and media advocacy. J Couns Psychol 2006;53:550-555.

14. Becker CB, Bull S, Schaumberg K, Cauble A, Franco A. Effectiveness of peer led eating disorders prevention: a replication trial. J Consult Clin Psychol 2008;76:347-354.

15. Becker CB, Wilson C, Williams A, Kelly M, McDaniel L, Elmquist J. Peer facilitated cognitive dissonance versus healthy weight eating disorders prevention: A randomized comparison. Body Image 2010;7:280-288.

16. Becker CB, McDaniel L, Bull S, Powell M, McIntyre K. Can we reduce eating disorder risk factors in female college athletes? A randomized exploratory investigation of two peer-led intervention. Body Image 2012;9:31-42.

17. Stice E, Rohde P, Durant S, Shaw H, Wade E. Effectiveness of peer-led dissonance based eating disorders prevention groups: Results from two randomized pilot trials. Behav Res Ther 2013;51:197-206. 
18. Perez M, Becker CB, Ramirez A. Transportability of an empirically supported dissonancebased prevention program for eating disorders. Body Image 2010;7:179-186.

19. Wallerstein NB, Duran B. Using community-based participatory research to address health disparities. Health Promot Pract 2006;7:312-323.

20. Stirman SW, Crits-Christoph P, DeRubeis RJ. Achieving successful dissemination of empirically supported psychotherapies: A synthesis of dissemination theory. Clin PsycholSci Pr 2004;11:343-359.

21. Steiner-Adair C, Sjostrom L, Franko DL, Pai S, Tucker R, Becker AE, Herzog DB. Primary prevention of risk factors for eating disorders in adolescent girls: Learning from practice. Int J Eat Disord 2002;32:401-411.

22. Sjostrom LA, Steiner-Adair C. Full of Ourselves: A Wellness Program to Advance Girl Power, Health and Leadership: An Eating Disorders Prevention Program That Works. J Nutr Educ Behav 2005;37(Suppl 2):S141-S144.

23. Mellanby AR, Rees JB, Tripp JH. Peer-led and adult-led school health education: a critical review of available comparative research. Health Educ Res 2000;15:533-545.

24. Stice E, Marti CN, Shaw H, Jaconis M. An 8-Year Longitudinal Study of The Natural History of Threshold, Subthreshold, and Partial Eating Disorders From a Community Sample of Adolescents. J Abnorm Psychol 2009;118:587-597.

25. Ciao AC, Loth KA, Neumark-Sztainer D. Preventing eating disorder pathology: Common and unique features of successful eating disorders prevention programs. Curr Psychiatry Rep 2014;16:453.

26. Neumark-Sztainer D, Butler R, Palti H. Eating disturbances among adolescent girls: Evaluation of a school-based primary prevention program. J Nutr Educ 1995;27:24-31 
27. Austin SB, Spadano-Gasbarro JL, Greaney ML, Blood EA, Hunt AT, Richmond TK, et al. Effect of the planet health intervention on eating disorder symptoms in Massachusetts middle schools, 2005-2008. Prev Chronic Dis 2012;9:E171.

28. González M, Penelo E, Gutiérrez T, Raich RM. Disordered eating prevention programme in schools: A 30-month follow-up. Eur Eat Disord Rev 2011;19:349-56.

29. Becker CB, Stice E. Sorority Body Image Program Group Leader Guide. New York, NY: Oxford University Press; 2008.

30. Fairburn CG, Beglin S. Assessment of eating disorders: Interview or self report questionnaire? Int J Eat Disord 1994;16:363-370.

31. Stice E, Ziemba C, Margolis J, Flick P. The dual pathway model differentiates bulimics, subclinical bulimics, and controls: Testing the continuity hypothesis. Behav Ther 1996;27:531-549.

32. Thompson JK, van den Berg P, Roehrig M, Guarda AS, Heinberg LJ. The Sociocultural Attitudes Towards Appearance Scale-3 (SATAQ-3): Development and validation. Int J Eat Disord 2004;35:293-304.

33. Cooper PJ, Taylor MJ, Cooper Z, Fairburn CG. The development and validation of the body shape questionnaire. Int J Eat Disord 1987;6:485-494.

34. Pook M, Tuschen-Caffier B, Brähler E. Evaluation and comparison of different versions of the Body Shape Questionnaire. Psychiatry Res 2008;158:67-73.

35. Garner DM, Garfinkel PE. The eating attitudes test: An index of the symptoms of anorexia nervosa. Psychol Med 1979;9:273-279. 
Figure 1. Participant flow by group (active or waitlist) and study flow over the academic school year for the intervention, one week post/waitlist assessment, and 3-month follow-up assessment

Time (school year)

September

\section{Peer-leader Training}

\section{Allocated to Active} Group (n= 25)
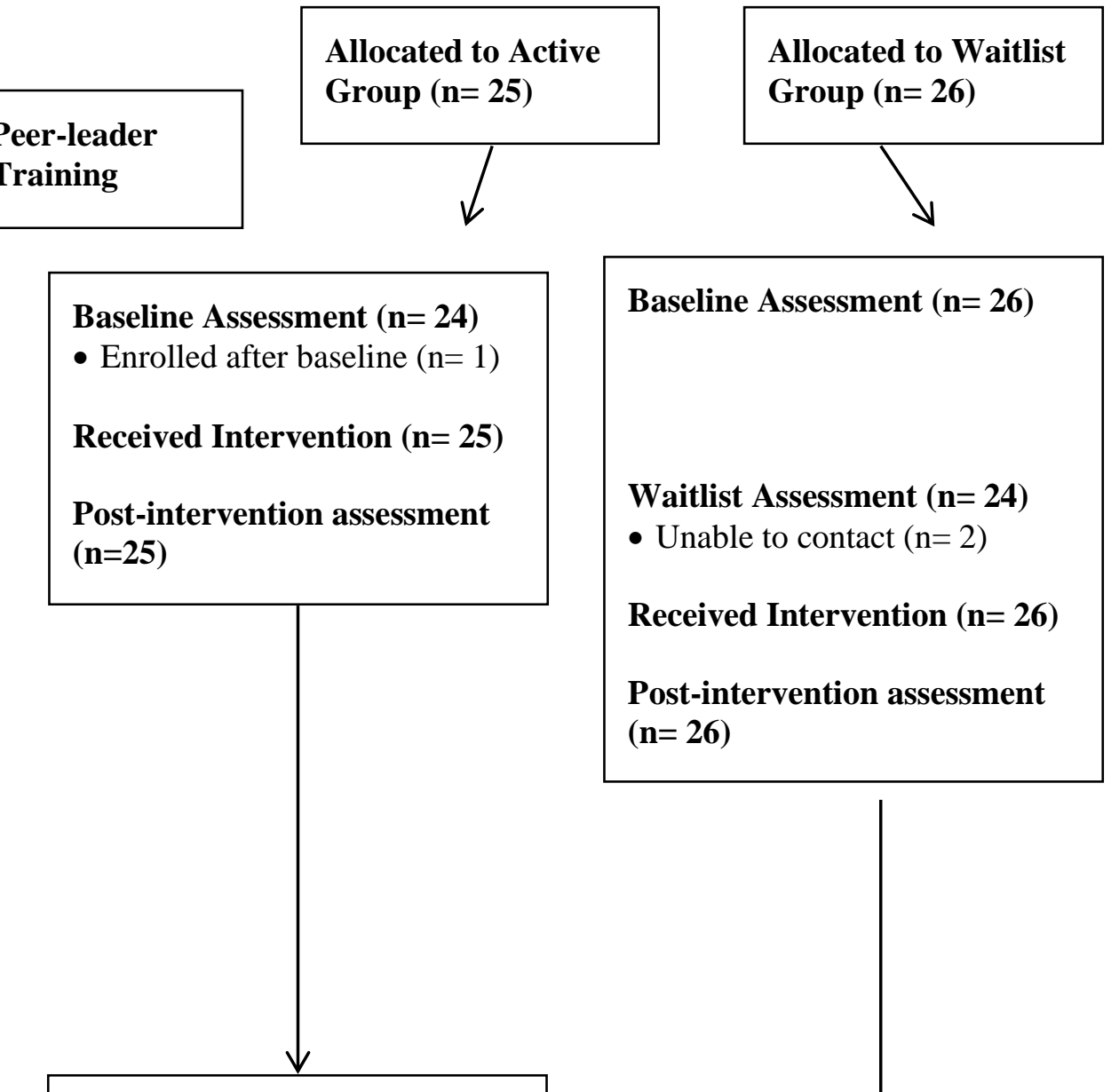

Follow-up Assessment

- Assessed $(n=23)$

- Unable to contact $(\mathrm{n}=2)$

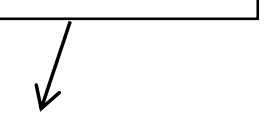

\section{Baseline Assessment (n= 26)}

Waitlist Assessment $(n=24)$

- Unable to contact $(\mathrm{n}=2)$

Received Intervention $(n=26)$

Post-intervention assessment $(\mathrm{n}=26)$

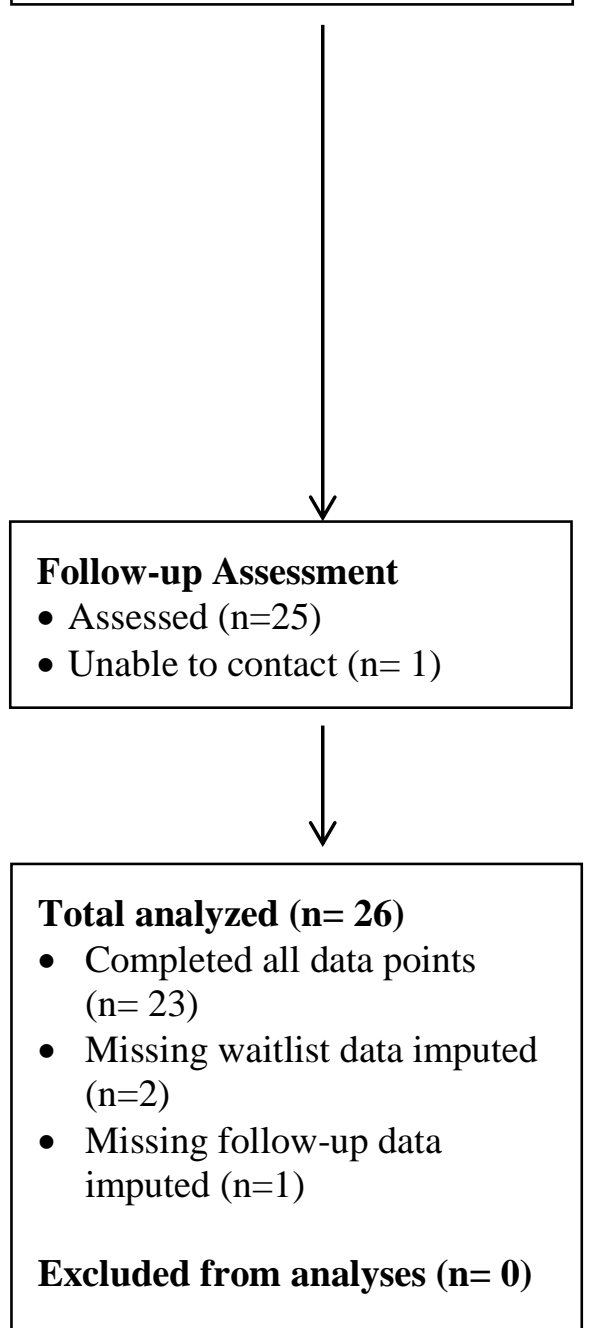

\section{Total analyzed $(n=24)$}

- Completed all data points $(n=22)$

- Missing follow-up data imputed $(n=2)$

Excluded from analyses $(n=1)$

- Incomplete baseline $(n=1)$
Follow-up Assessment

- Assessed ( $n=25)$

- Unable to contact $(n=1)$

Completed all data points

Missing waitlist data imputed $(n=2)$

Missing follow-up data imputed $(n=1)$

Excluded from analyses $(n=0)$ 
Table 1. Risk factor outcome scores and test statistics for pre-post intervention vs. waitlist comparison and change across the total sample from baseline through 3-month follow-up

\begin{tabular}{|c|c|c|c|c|c|}
\hline & & Baseline & Post & Follow-up & Test Statistic \\
\hline & & $M(S D)$ & $M(S D)$ & $M(S D)$ & \\
\hline \multicolumn{6}{|l|}{ Internalization } \\
\hline \multirow[t]{3}{*}{ IBSS-R } & Active & $3.28(0.55)$ & $2.79(0.64)$ & -- & \multirow{2}{*}{$\begin{array}{l}F(1,48)=17.47, p=.000 \\
\text { partial } \eta^{2}=.27\end{array}$} \\
\hline & Waitlist & $3.33(0.54)$ & $3.37(0.71)$ & -- & \\
\hline & Total & $3.31_{\mathrm{a}}(0.54)$ & $2.88_{b}(0.72)$ & $3.21_{\mathrm{a}}(0.72)$ & $\begin{array}{l}F(2,48)=12.84, p=.000 \\
\text { partial } \eta^{2}=.35\end{array}$ \\
\hline \multirow[t]{3}{*}{ SATAQ-3 } & Active & $40.79(9.54)$ & $31.04(9.24)$ & -- & \multirow{2}{*}{$\begin{array}{l}F(1,48)=28.38, p=.000 \\
\text { partial } \eta^{2}=.37\end{array}$} \\
\hline & Waitlist & $40.46(11.34)$ & $38.75(11.09)$ & -- & \\
\hline & Total & $40.62_{a}(10.41)$ & $34.70_{b}(10.89)$ & $39.60(9.71)_{\mathrm{a}}$ & $\begin{array}{l}F(2,48)=12.80, p=.000 \\
\text { partial } \eta^{2}=.35\end{array}$ \\
\hline \multicolumn{6}{|c|}{ Body Dissatisfaction } \\
\hline \multirow[t]{3}{*}{ BSQ-8 } & Active & $2.45(1.08)$ & $1.81(0.64)$ & -- & \multirow{3}{*}{$\begin{array}{l}F(1,48)=8.80, p=.005 \\
\text { partial } \eta^{2}=.16 \\
F(2,48)=10.65, p=.005 \\
\text { partial } \eta^{2}=.31\end{array}$} \\
\hline & Waitlist & $2.81(1.20)$ & $2.72(1.30)$ & -- & \\
\hline & Total & $2.64_{\mathrm{a}}(1.15)$ & $2.12_{b}(1.04)$ & $2.13 \mathrm{~b} \quad(1.11)$ & \\
\hline \multirow[t]{3}{*}{ EDEQ-WSC } & Active & $1.71(1.54)$ & $1.17(1.18)$ & -- & \multirow{3}{*}{$\begin{array}{l}F(1,48)=3.65, p=.062 \\
\text { partial } \eta^{2}=.07 \\
F(2,48)=9.99, p=.000 \\
\text { partial } \eta^{2}=.29\end{array}$} \\
\hline & Waitlist & $2.45(1.83)$ & $2.34(1.82)$ & -- & \\
\hline & Total & $2.09 \mathrm{a}(1.72)$ & $1.57_{\mathrm{b}}(1.49)$ & $1.45_{b} \quad(1.30)$ & \\
\hline \multicolumn{6}{|l|}{ Eating Pathology } \\
\hline \multirow[t]{3}{*}{ EAT-26 } & Active & $1.93(0.81)$ & $1.64(0.71)$ & -- & \multirow{2}{*}{$\begin{array}{l}F(1,48)=6.89, p=.012 \\
\text { partial } \eta^{2}=.13\end{array}$} \\
\hline & Waitlist & $2.10(0.71)$ & $2.14(0.97)$ & -- & \\
\hline & Total & $2.02_{\mathrm{a}}(0.76)$ & $1.77_{b}(0.77)$ & $1.91_{\mathrm{a}}(0.88)$ & $\begin{array}{l}F(2,48)=8.33, p=.001 \\
\text { partial } \eta^{2}=.26\end{array}$ \\
\hline
\end{tabular}


Table 1, continued. Analysis of risk factor outcomes over time

\begin{tabular}{|c|c|c|c|c|c|}
\hline & & Baseline & Post & Follow-up & Test Statistic \\
\hline & & $M(S D)$ & $M(S D)$ & $M(S D)$ & \\
\hline \multirow[t]{3}{*}{ EDEQ-Total } & Active & $1.39(1.32)$ & $0.91(0.99)$ & -- & \multirow{2}{*}{$\begin{array}{l}F(1,48)=3.26, p=.077 \\
\text { partial } \eta^{2}=.06\end{array}$} \\
\hline & Waitlist & $2.01(1.57)$ & $1.90(1.52)$ & -- & \\
\hline & Total & $1.71_{\mathrm{a}}(1.47)$ & $1.27_{\mathrm{b}}(1.24)$ & $1.19_{\mathrm{b}}(1.17)$ & $\begin{array}{l}F(2,48)=9.90, p=.000 \\
\text { partial } \eta^{2}=.29\end{array}$ \\
\hline \multicolumn{6}{|l|}{ Dietary Restraint } \\
\hline \multirow[t]{3}{*}{ EAT-Diet } & Active & $2.18(1.13)$ & $1.69(0.86)$ & -- & \multirow{2}{*}{$\begin{array}{l}F(1,48)=11.91, p=.002 \\
\text { partial } \eta^{2}=.20\end{array}$} \\
\hline & Waitlist & $2.36(1.01)$ & $2.33(1.20)$ & -- & \\
\hline & Total & $2.28_{\mathrm{a}}(1.07)$ & $1.85_{\mathrm{b}}(0.99)$ & $2.03_{\mathrm{b}}(1.10)$ & $\begin{array}{l}F(2,48)=13.63, p=.000 \\
\text { partial } \eta^{2}=.36\end{array}$ \\
\hline \multirow[t]{3}{*}{ EDEQ-R } & Active & $0.76(1.08)$ & $0.38(0.70)$ & -- & \multirow{2}{*}{$\begin{array}{l}F(1,48)=1.03, p=.315 \\
\text { partial } \eta^{2}=.02\end{array}$} \\
\hline & Waitlist & $1.13(1.35)$ & $1.02(1.32)$ & -- & \\
\hline & Total & $0.95_{\mathrm{a}}(1.23)$ & $0.67_{\mathrm{b}}(1.05)$ & $0.68_{b}(1.16)$ & $\begin{array}{l}F(2,48)=3.73, p=.031 \\
\text { partial } \eta^{2}=.13\end{array}$ \\
\hline
\end{tabular}

Note: For each outcome variable, the test statistic associated with the active and waitlist mean refers to the group by time interaction of active vs. waitlis comparison (active $n=24$; waitlist $n=26$ ). The test statistic associated with the total sample mean refers to the main effect of the baseline-post-followup within-participants comparison across the entire sample (Total $n=50$ ). Means within the same row with different subscripts indicate significant differences between time points $(p<.05)$. Original 1-6 scoring scale of EAT-26 was preserved to maintain as much individual variation within scores as possible; two EAT-26 items were removed in the total scale (items 13 and 26) and one item was removed in the EAT-Diet subscale (item 26) due to low item-total correlation. 


\section{Acknowledgements}

This study was partially funded by a fellowship from the American Association of University Women. 